\title{
How might we simulate a riverside experience through virtual collaboration?
}

\author{
Zoe Latham \\ University of Plymouth, United Kingdom \\ Linda Ward \\ University of Plymouth, United Kingdom
}

\begin{abstract}
In this paper we explore convergences between personal experiences with water and film-making. Employing a cross-disciplinary collaborative dialogue, Latham and Ward create a virtual stream, that explores the language of each other's praxis, in architecture and film. McLuhan's notion that: "The reader is the content of any poem or of the language [s]he employs, and in order to use any of these forms, [s] he must put them on," (McLuhan 1971, 520) provides a signpost for the immersive experience we seek in our understandings of river, and in our approaches to disciplinary practice.

During lockdown in the UK, a displaced, virtual riparian conversation evolved. Through online exchanges of particular ways of seeing and using film as method, new flows in the space between film and architecture, making and experiencing, emerge as a site for experimentation and interrogation. Through remediation and overlay of individual and shared embodied water experience, a conflated flux of differences point towards a new river paradigm.
\end{abstract}

Keywords: Collaboration, Water, River, Experience, Film, Architecture, Embodiment, Cross-disciplinary, Dialogue, Digital

\section{Introduction}

It's not by chance that both researchers find themselves on the water, a place of unique, unpredictable motion, a place where what they know and make in their disciplines may become less predetermined and they become dislodged from a sense of separation from nature and from their watery selves. 'The water that gave us life is also the water that we humans in turn carry with us, in us' (Neimanis, Garrard \& Kerridg 2017, 122).

Ward and Latham work singularly and together to create digital moving image work to explore a relationship to waterscape, memory and place. The natural world with water embodying 'social, cultural and spiritual dimensions ... has long held a central role in religion, literature, art, medicine, and recreation' (Barker and Coutts 2016, 8). Ward and Latham experience a heightened sense of connection with water; it is a potent research area for both in different ways.

Ward has drawn on personal experience of being in water when the tour boat she was on with her late mother was caught in a storm and passengers had to jump into the sea and swim for safety. This is bound up in her memories of her mother and the relationship between the archetypal mother Mary figure (as Stella Maris) and her relationship to the ocean. Her practice-led research has concerned and been made in proximity to the sea and rivers. On the river, Ward is interested in the visual, the visible and the invisible elemental force of water as she connects it with memories of her mother who swam a great deal. Moving image work, insight and knowledge have come from engaging with water ${ }^{1}$. As Roberts and Philips (2018) state, 'Water is essential to all life as we know it. As such, it seems a good place to start with an attempt to think about porosity of human experience.'

Throughout her architectural praxis Latham draws upon embodied ways of experiencing place, reflecting most recently on riverscapes, through the ritualised act of fly-fishing. Through watercraft, turning riverbed stones to reveal dormant entomological creatures, casting through winds and navigating hidden riparian ecologies Latham experiences a greater sense of connection and relation to the world; ' $[\mathrm{t}] \mathrm{he}$ idea that a tiny change in our surroundings has broader impact is commonly talked about, but in fly-fishing you see it actually happen' (Gooley 2016, 87). This attunement to broad notions of landscape begins to inform an architectural sensibility that requires a slowing down of the design process and a listening, observing and most importantly an engagement with the people and place around. Physicist, James Wells, speaks of these kinds of observations in the search for the Higgs boson:

Our knowledge of nature and how it works is based on observations. What if we can't see everything? What might we be missing out on? There could be a 'hidden world' out there (cited in Sample 2010, 9)

While individual trajectories and starting points are quite different, the communal focus of water has brought Ward and Latham together along with a wider community of water inspired thinkers - most recently at a gathering for the Association for the Study of Literature and Environment (ASLE) 'Flows of entanglement: how rivers shape identity' conference hosted at the University of Plymouth ${ }^{2}$. Ward and Latham return to water, the fluidity and constant change providing endless possibility. Water in multiple forms captures the imagination, evident in a recent run of popular books that focus on the joys of interactions with water (and implicitly nature) for instance wild swimming (Deakin 2000), sea travel and intellectual exploration of the substance (Jha 2015), learning how to 'read water' (Gooley 2016).

Veronica Strang argues that properties of water exist through relations and meaning, her aim is to show how water's material agency is a challenge to the dominating nature-culture dualism and its alienation of human kind from 'the other' (Roberts \& Phillips, 2018). 
The consideration of water in both researcher's practice blurs the boundary between internal and external experience - we see into it what we are looking for and we take from it what we need, what is our perception of water, what it scientifically is, exists in dialogue.

An increase in research around relations to water recognises multiple disciplinary outlooks and perspectives, as well taking into consideration social and cultural context (e.g., Strang 2004, 2010; Krause and Strang 2016). However, despite the clarion calls for 'integrations', 'interdisciplinary' 'multidisciplinary', 'more than human research' etc. the outputs of scientific/ technical policy-related studies rarely mention the personal, the embodied, the intimate, the poetic and the spiritual, or they judge these to be unimportant to techno-political strategizing over a precious resource (Roberts \& Phillips, 2018). It is in this opening to multidisciplinary, personal experience and practice without prescribed outcomes, that this paper aims to investigate further.

Ward and Latham appreciate synergies between their research and have begun to collaborate to produce work that is open to possibilities and thinking around the themes of water, meaning and embodiment. This connection has since resulted in a joint presentation 'Our Selves the Water' where they created a single screen moving image work, Water Screening (2019) and an interaction of light through water in which audience members participated in creating a visual interference of the spatial projection processes. The moving image piece, Water Screening (2019), became a steppingstone to the shared concerns in their further work Digital River (2021), discussed in this paper.

Fieldwork began on the River Dart, prior to UK lockdowns, is the primary source of their project. The river they visit is quite remote. Parker and Moore note 'for a scientist, the trees and animals living in the river corridor were an integral part of what constituted the river, as relevant as the watercourse itself' (Parker and Moore 2016, 141). They share the river with flora, fauna and animals. 'Cows trudge down to the water and gradually demolish the river bank leading to shallower, wider streams' (Gooley 2016, 72). In their fieldwork on Dartmoor this has been the researchers' experience, the trodden banks have influenced the geography of their exit from and entry into the river.

\section{Notes on the embodied experience of fieldwork by Ward:}

When I stand knee-high in the shallows with my camera lens intently following ripples and light, I become immersed by the sensation of cold water rushing around my legs and with my face close to the surface, the noise caused by water mixing with air becomes a steady roar.

When I see Zoe in the water, venturing with her camera I feel we are seeking different things differently and yet the river itself acts as a place of convergence. On and at the water's edge, immersed in our ideas we have moments in which our thinking and practice converges and diverges.
I like to place my eye at the surface of the water, at the cusp of perception, to film significant submerged objects that hold memories of motherhood and home. Water offers something unknown and ungraspable, 'Water [...] calls to us too, from a realm of materiality that is also, simultaneously, more-than-human and beyond any kind of intentional grasp' (Neimanis, Garrard \& Kerridge 2017, 22). Cows reach the water and the first time they cross we stay in the water with them for some time.


Image 1 - Fieldwork on Dartmoor (2021) Ward \& Latham 


\section{Notes on the embodied experience of field work by Latham:}

Enduring the tug of the water, fighting the sun's glare and the countering a wind that wants to eat my cast requires a deep focus on what is around me that all that is inessential drifts away - leaving me whole and healed. Fly-fishing allows me conceptualise landscapes in my mind, reclaiming a space on the land that my body, cast and line connects to. Although my physical presence in the landscape is temporary, it is forever a place in my mind. The author Verlyn Klinkenbourg fishes the same waters as I once did in New York and reflected on the sport in relation to everyday life reaffirming what I also believe,

Most of what the working day offers us - most days, that is - don't require the fullness of our being, and so we live partially, economically. You'd think that the effort needed to fish well - to cast precisely, to notice all the things that need noticing - would require an even thinner slice of ourselves. But that isn't the way it works. We focus intently. A lighter tippet. A smaller fly. A cleaner drift. Hour after hour. And it is the focus that frees us to be a little bit larger than we usually get to be. (Sautner \& Klinkenborg 2007, p.xxi)

\section{Collaborating Online, New Methods}

In the UK Lockdown during the Covid-19 Pandemic away from the water the memory and function of being in and of water remained a strong incentive to create. Taken out of context or out of the field, the researchers continued sharing practice through online video calls and sharing works with one another via screen sharing - this took the form of films, audio, film stills and drawings - sometimes overlaid all at once. Although the bodies of water were smaller and more domestic in scale - notions of light, movement, and miscibility - still flowed. As noted by Neimanis, quoting Deleuze and Guattari, the experience of water had to come from within, finding new references and forms of creatively engaging with our individual subjects through water:

'When the seas dried, the primitive Fish left its associated milieu to explore land, forced to 'stand on its own legs', now carrying water on the inside, in the amniotic membranes protecting the embryo' (Deleuze and Guattari 1987, 55 cited in Neimanis, Garrard \& Kerridge 2017, 109)

During the summer of 2020, A new kind of communication unfolded via Tumblr, a multimedia short-form blog. Ward and Latham moved this exchange onto the digital platform, giving a presence to the act of sharing that we could further reflect upon. This experiment was founded on a generous attitude to further ideas grown from field experiences without preconceptions, in an attempt to develop the notion of flow - as a digital, visual, poetic conversation. The dynamic of this process may well have provoked a competitive exchange, yet the participants strove to adopt a collaborative and playful approach as reflected in the work of Keith Johnstone:

When the actor concentrates on making the thing he gives interesting, each actor seems in competition, and feels it. When they concentrate on making the gift they receive interesting, then they generate warmth between them. (Johnstone 2017, 101)

Looking at the terrain of the river and the flow contained yet moving between two banks, the researchers provided the course of the flow of conceptual and material ideas through this online platform. Between the banks of the metaphorical river, the two researchers continued investigating and creating new realms of experience through making film and architecture emerging into: 'the in-between space between architecture and film to locate some important pockets of existing practice and suggest lines of future trajectories' (Troiani, I., Campbell, H. 2020, 3). This in-between space became fertile ground for raising questions about our disciplines, what flows between film and architecture? How do our languages converge? How might we simulate a riverside experience through this cross-disciplinary, virtual collaboration?

This process began with each participant presenting a still or moving image derived from Water Screening (2019). Each image had a comment by the person posting in the form of notes and thoughts about the process focusing on the particular image. Having posted the researcher then waited for a response from the other researcher. This waiting became just as much a part of the process in that it generated both reconsideration of the post and expectation and anticipation of the response.

The Tumblr exchange embodied researcher's initial interests and revealed a very different digital - formulation of a flow of ideas. As each 'gift' was received the researchers were viewing the images in extreme close up drawing from rituals and contextualisation, place and concern with what's next, and river-like, moving with some urgency to perpetuate the flow. Their various embodied field experience shifted to focus on thought, fingers typing, employing basic digital filmic processes of overlay, dissolves, split screening - remediating the initial experience of the water: embodiment shifted. Relating to Veronica Strang's notion of water existing through relation and meaning, Maurice Merleau-Ponty similarly remarks on the significance of experience and calls for adaptation in understanding shifting modes of existence:

\footnotetext{
... existence is embodiment - that we only know the world through our experience of being embodied. But as that experience shifts - as it inevitably does - our methods for understanding that experience need to be adequate to that shifting (Neimanis, Garrard \& Kerridge 2017, 59).
} 
On the first text of the Tumblr the words 'light generation' appear, and this unconsciously works as a metaphor for the energy developed between the participants that might be unseen in the work but was very much a part of the 'flow' and illumination felt by the participants. During the waiting time each researcher was subject to their own imaginings as to how the 'conversation' was progressing but importantly what the recipient might be thinking, what she might choose to present as the next step: what words, what image? What might she be seeing differently?

...we are constantly confronted by difference the different rates, speeds, pathways, and bodily expressions that water takes on. This variability is then diffracted through vastly different ways in which water affects our (different) bodies, and we, in turn, affect the waters with which we live. We could even say that water can only serve as a connector because it expresses or facilitates difference. Through the continued expressions of watery difference, bodies proliferate and transform - always seeking out new expressions of water embodiment (Neimanis, Garrard \& Kerridge 2017, 67)

As each researcher put forward their contributions to the digital dialogue, the method naturally embodied the ideas of Marshal McLuhan when he says, "[t]he reader is the content of any poem or of the language [s] he employs, and in order to use any of these forms, [s]he must put them on". (McLuhan 1971, 520).
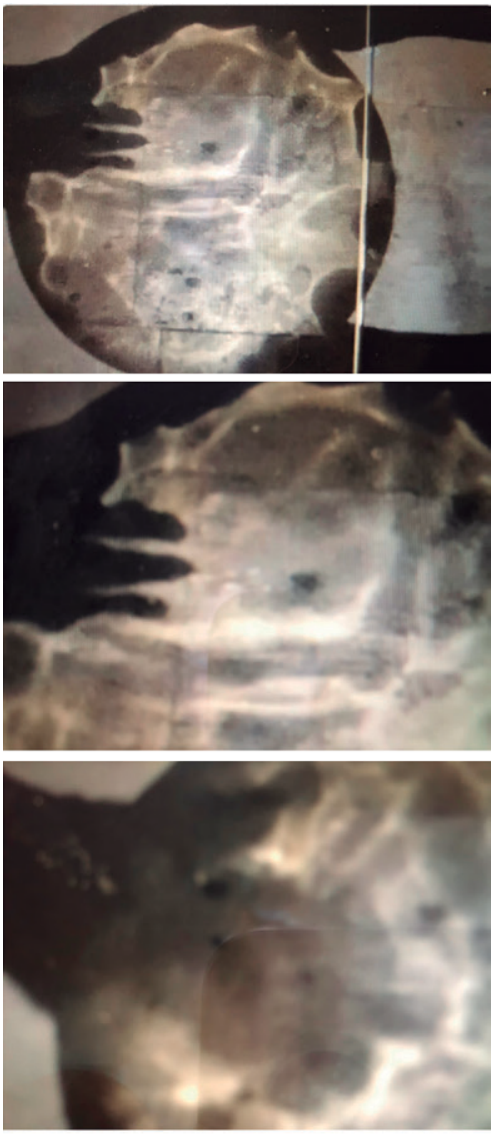

IW

Hand held

Hand holding

Hand $\mathrm{H} 20$

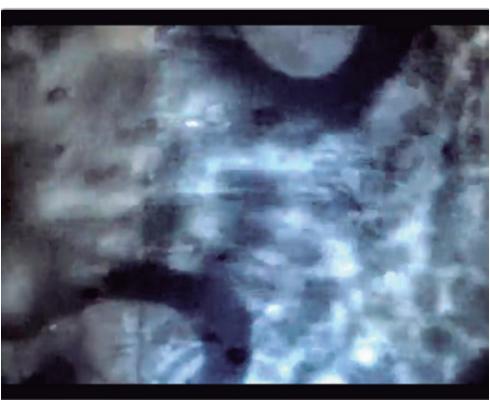

Image 2 - Ourselves the Water Tumblr Feed (2020) Ward \& Latham 
The notion of difference here relates to the practice of each researcher. Ward has a disposition to film at very close quarters with a deep scrutiny of subjects, using extreme close shots moving across subjects to reveal details of landscape within landscapes, obscuring and revealing visions within her shots. Her work is hand-held and subject to remediation across digital and analogue technologies. Latham approaches filmic explorations from a cartographic background, layering plan views of a journey with personal memories and sequential photographs. She uses split screen to intimate the collision and difference of spaces within the composition. Roughly described here, but these differences became a site of convergence as the project progressed with each 'trying on' the others methodology, giving to and drawing from the other. Methodological processes that became shared in the collaboration include the remediation of images by Ward and the process of palimpsest by Latham, which both researchers employed.

In 'putting on' one another's methods of making and ways of looking to the water, the dialogue progressed with each contribution being pushed and informed by the previous one, simultaneously reaching forward for a response from the other. Visual and textual forms developed in the dialogue. Still and moving images and plays on sound honed in on theoretical ideas of interest - embodiment, sensing, re-filming and emergence. These became the substance of the ensuing single screen video. Ward and Latham play and experiment with one another's methods, as Fink describes:

In the creativity of pure play, a person experiences himself as the playmate in the play of the world... Playing he dwells in the play of the building and destroying, the joining and the separating, the letting-be and annihilating of the world (Fink 1992, 193-4 as translated in Homan 2013, 289).

In this, a sense of engagement - even excitement - was generated. A form of participatory energy that grew through the process of production. This was a welcome and stark contrast to the emerging online modes of research and teaching that had become very monological under UK lockdowns (2020-2021).

\section{Miscible Narrative}

The containment of ideas by the Tumblr exchange formed a digital flow of words, moving images and stills akin perhaps to the aesthetic properties of water. This holistic view gave the researchers an opportunity to review and analyse the processes of transformation that took place in the work remade on-line. Considered now, something new, a narrative where one another's work reformulates the other; becoming miscible through the element of water, mixing into a new kind of homogeneous solution - each offering an extension of the previous gift. The Tumblr dialogue arrives at a place of 'informed spontaneity', a mutual appreciation and aesthetic, combined insight and intuition; '[t]he process involves risk, the courage to embrace failure, to un-make and re-make, combined with the lightness of play' (Ravetz 2017, 129).

The researchers also used a digital scripting application (Fade in) to formulate a further conversation, venturing into a new mode of communication with a more detailed improvised exchange. The use of narrative allowed articulation of 'semi-formed concepts' that were 'at our fingertips awaiting activation', acknowledging these experiences as 'more than conceptual fantasy or metaphor, [but as] imaginative 'interventions' (Braidotti 2011, 14). Fusing together individual experiences, and ways of producing film 'syncretic assemblages' of knowledge allows understanding of 'the ways in which our bodily matter is implicated in a world that cannot be adequately grasped through one mode of inquiry alone' (Alaimo 2010, 19 in Neimanis, Garrard \& Kerridge, 2017).

\section{Notes from the Fade-in conversation - digital field work:}

\section{$L W$}

Thinking about what the images suggest... a 'slug' as in the term used in broadcasting to name an item for transmission - all items were given a 'slug' or name. There is an initial slug like appearance and a gluey viscosity and slug/glug is an immediate rhyme ... it flows like a children's rhyme, a bit like 'a ring of roses' and what we are looking at is gathering ... becoming a different light structure ... light making, making light of the situation, perhaps or the literal construction what we are seeing - as in - it is made by light.

\section{ZL}

Dark and light, increased contrast. The edges are sharper and bolder. Seeing slug glug is seeing form and substance. The edges are continually shifting, making and remaking boundaries and shapes. Although pulling apart the water stays as one. Adding water and uneasy hands create a continual movement on the slippery screen.

\section{Digital River}

Realising the short textural comments in Tumblr may have been perceived as definitive, the researchers sought to find another means for opening out the discussion in relation to the screen. Using the movement of scrolling through the Tumblr page, and the editing in of a single continuous shot from the River Meavy, the unruly quality of motion and water worked to undo the fixity of the text, and thereby new places of discussion were opened in the piece, Digital River (2021). This process of exploration aligns with Tarkovsky's view of the work of cinema; 'it is only a question of searching each time searching out afresh the path, the channel to be followed.' (Tarkovsky 1986, 80). Time and light are common considerations of the filmmaker and the architect as is movement in the encounter with geographical space and filmed space. Erika Balsom (Balsom, published in Govett- Brewster 
Art Gallery 2018, 17) writes, 'Unlike any medium before it film promised to capture traces of the world in time, registering moments and movements', in explaining phenomenology Bortoft says:

I stood on a bridge, looking down stream at the river flowing away from me. For some reason this made me feel uneasy and I crossed to the other side to look at the river flowing towards me. This felt better, and I spent some time there looking upstream. I began to be drawn into the experience of looking, plunging with my eyes into the water flowing towards me. When I closed my eyes, I sensed the river streaming through me and when I opened them again, I found that I was experiencing the river flowing towards me outwardly and through me inwardly at the same time (Henri Bortoft 2012, 18)

Through the researchers' evolving digital communication process, the phenomena of being on the bank, swimming and casting lines in the river and observing the action of water with cameras evolves into a flow of phenomena on the screen. In Digital River (2021) the '...river can offer an elemental summons: to slip in, to be submerged...a river has a destination and there is something about the certainty with which it travels that makes it very soothing' ( Laing 2011, 7).

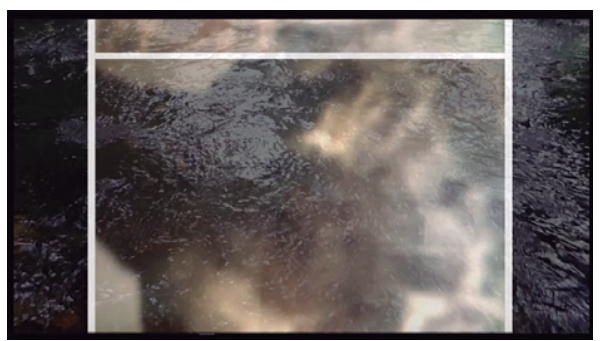

Image 3 - Still from Digital River (2021) Ward \& Latham

Just as Salman Rushdie points out, a softening of the boundary between the world and the self takes place in artistic experience:

Literature is made at the boundary between self and the world, and during the creative act this borderline softens, turns penetrable and allows the world to flow into the artist and the artist flow into the world' (Pallasmaa, 2009).

The idea of a digital river is somehow boundless, with ideas, methods and imagery flowing in and out of the real, imaginary, digital and material word. This softening of the existential boundary, 'the fusion of the world and the self, object and subject, takes place in every meaningful artistic work and experience" (ibid).

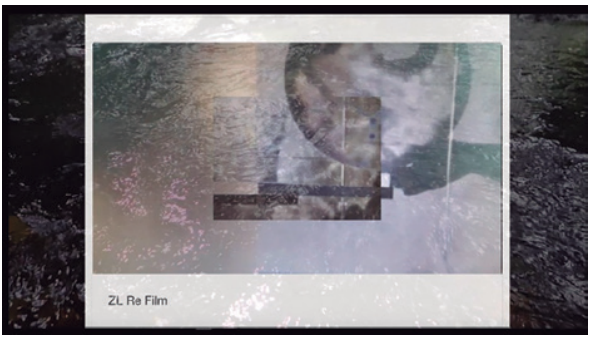

Image 4 - Still from Digital River (2021) Ward \& Latham

\section{Conclusion}

In the pursuit of mutual research development, researchers Ward and Latham sought to continue working together with their local waters. Having become displaced from this physical engagement due to lockdown restrictions, they questioned whether they could simulate a riverside experience through virtual collaboration? The Digital River (2021) emerged as a freeing and creative space whereby researchers have been able to continue, and further develop, forms of reflexive praxis - evolving one's own sense of being, understanding of place and embodied phenomena through dialogue with the other.

Through this form of communication, the project progressed ideas connected by water and layers of remediation became more miscible but also colloidal: together yet separate in the unfixed, open form of the Digital River (2021). Gooley notes that 'in the slowest patches of river, where the water almost comes to a halt the very finest silt is deposited (Gooley 2017, 76). As a river loosens it transports layers of sediment along its course, the elements of form in the idea of a digital river tease out and imply possible meanings, some to be carried forward and others to sink to the river bed, the containment of the form. Laing writes, 'there is a mystery about rivers that draws us to them, for they rise in hidden places and travel by routes that are not always tomorrow where they might be today' (Laing 2011, 7). Having conveyed something of their process and its trajectory so far, the researchers are surveying other digital formats or 'streams' to further expand ideas of digital flow and embodiment through communication. They also present the moving image work Digital River (2021) to audiences, noting McLuhan's emphasis on the viewer as co-creator; the content of the work, and wait to find the rivers reach: in what ways its form is amplified and changed.

Please follow link to Digital River (2021) Dir: Ward and Latham: https://vimeo.com/541851730/6a1a11b37f 


\section{Notes}

${ }^{1}$ Pearl (2017) digital moving image work, Mary Sea (2017) analogue and digital moving image work, Mary River (2020) digital moving image work, Hydrangea Sea (2021) digital moving image work.

${ }^{2}$ 'Flows of entanglement: how rivers shape identities.

This panel invites scholars from a diverse range of disciplines to consider the entangled and fluid ways in which rivers shape identities', more information to be found here: https://www. plymouth.ac.uk/whats-on/flows-of-entanglement-how-riversshape-identities

\section{Bibliography}

Balsom, Erika. 2018. An Oceanic Feeling: Cinema and the Sea. Govett-Brewster Art Gallery.

Barker, R. and Coutts, R. 2016. Aquatecture: Buildings and Cities Designed to Live and Work with Water. RIBA Publishing.

Bortoft, Henri. 2012. Taking appearance seriously: The dynamic way of seeing in Goethe and European thought. Floris Books.

Braidotti, Rosie. 2011. Nomadic Subjects, New York: Columbia.

Deakin, Roger. 2021. Waterlog: A swimmers journey through Britain. Tin House Books.

Fink, Eugene. 2016. Play as symbol of the world: And other writings. Indiana University Press.

Gooley, Tristan., 2016. How to read water: Clues and patterns from puddles to the sea. The Experiment.

Krause, Franz, and Veronica Strang. 2016. "Thinking relationships through water." Society \& Natural Resources 29, no. 6: 633-638.

Jha, A., 2015. The water book. Hachette UK.

Johnstone, Keith. 2017. Impro: Improvisation and the Theatre, Bloomsbury Publishing.

Laing, Olivia. 2011. To the River: A Journey Beneath the Surface. Edinburgh. Canongate Books.

McLuhan. 1971. in: "Roles, Masks, and Performances, New Literary History", Vol. 2, No. 3, Performances in Drama, the Arts, and Society (520)

Neimanis, A., Garrard, G. \& Kerridge, R.. 2017. Bodies of Water: Posthuman Feminist Phenomenology. Bloomsbury Academic.

Pallasmaa, Juhani. 2009. The thinking hand: Existential and embodied wisdom in architecture. Chichester: Wiley.

Parker, $\mathrm{K}$ and Moore. 2016. Filming the river: memories of the tidal Tamar

Ravetz, A., Kettle A., Felcey H,. 2013. A. eds., 2013. Collaboration Through Craft. A\&C Black.

Roberts, L. \& Phillips, K. 2018. Water, Creativity and Meaning: Multidisciplinary understandings of human-water relationships. Taylor \& Francis.

Parker, Kayla, \& Moore Stuart. 2016. Filming the River: memories of the tidal Tamar. S Edições Cine-Club de Avanca Edition 7, (eds) Costa Valenta A, Capucho, R. AVANCA I CINEMA 2016 Avanca, Portugal.

Sample, lan. 2010. The hunt for the hidden universe (No. PRESSCUT-S-2010-3, pp. 8-11).

Sautner, S. \& Klinkenborg, V. 2007. Upriver and Downstream: The Best Fly-fishing and Angling Adventures from the New York Times, Harmony Books.

Strang, Veronica. 2010. "Water, culture and power: anthropological perspectives from 'down under'." Insights, Journal of the Institute of Advanced Study 3, no. 14, 2-26.

Strang, Veronica. 2004. The meaning of water. Berg Publishers.
Tarkovsky, Andrey, and Kitty Hunter-Blair. 1989. Sculpting in time: reflections on the cinema. University of texas Press.

Troiani, I. and Campbell, H. eds. 2019. Architecture Filmmaking. Intellect Books. 